\title{
GESTIÓN DE LA ESCUELA Y LA EDUCACIÓN EN LATINOAMERICA: ANÁLISIS DE LA REALIDAD POLÍTICA
}

\author{
Cesar Gerónimo Tello* \\ Maria de Lourdes Pinto de Almeida**
}

Resumen: En el contexto del mundo del trabajo, podemos decir que la característica principal es la producción de fuerza capitalista, que han tomado la forma de mercancía, por lo que el trabajador es un simple objeto de la producción y la escuela posee un modelo de gestión en condiciones de producción. Este artículo tiene la intención de pensar la escuela como un lugar de tolerancia y de respeto que propicie el desarrollo de una cultura democrática, por lo que su funcionamiento alienta la participación de todos en la toma de decisiones. El trabajo de la escuela, desde la gestión, en muchas ocasiones, pierde el sentido de espacio de intercambio, construcción y relación social y se asume en las condiciones del mercado y de la producción.

Palabras clave: Gestión Escolar en América Latina. Educación y Gestión. Escuela y Gestión en América Latina.

\section{School management and education in Latin America: an analysis of reality from politics}

Abstract: In the context of the world of work is the main feature that capitalist production force has taken the form of market workers and thus become a mere object of production. Thus, the school plays a management model in terms of production. This

\footnotetext{
* Profesor e Investigador de la Universidad Nacional de Tres de Febrero, Argentina; Director de la Red Latinoamericana de Estudios Epistemológicos en Política Educativa; Sede Rectorado Mosconi, 2736, Sáenz Peña (B1674AHF), Buenos Aires, Argentina; ctello@untref.edu.ar

*** Pos Doctora en Políticas Educacionales por la Universidade Estadual de Campinas; Magíster y Doctora en Historia, Filosofía y Educación por la Universidade Estadual de Campinas; Profesora de la Universidade do Oeste de Santa Catarina; Pedagoga e Historiadora; Rua Getúlio Vargas, 215, Flor da Serra, 89600-000, Joaçaba, Santa Catarina; malu04@gmail.com
} 
paper proposes think the school as a place of tolerance and respect encouraging the development of a democratic culture, so that it does encourage the participation of all in decision-making. The schoolwork done in management, most of the times, lost sense of swap space, construction, and social relationship and is taken in terms of market and production.

Keywords: School Management in Latin America. Education and Management. School Management and Latin America.

\section{INTRODUCCIÓN}

El propósito de este trabajo es analizar determinadas particularidades teóricas acerca de la gestión educativa en la realidad latinoamericana.

Ahora bien, la categoría temática de gestión educativa, como campo disciplinar, data de los años sesenta en Estados Unidos, de los años setenta en el Reino Unido y de los años ochenta en América Latina. En cada una de estas regiones fue adquiriendo distintos matices y debemos considerar que desde la perspectiva clásica anglosajona la gestión educativa de las instituciones posee un fuerte carácter técnico instrumental asociada al direccionamiento y a los resultados.

Vivimos una crisis del proceso civilizatorio donde el mundo es abrumador y peligroso. Hay una visible banalización de la vida. La economía globalizada transforma en tiempo real el propio principio de las relaciones humanas y de la vida social. Por lo tanto, la nueva "era de mercado", según Ferreira (2003, p. 11) “[...] se presenta como la única vía posible de sociabilidad que, lógicamente, se torna cada vez más utilitarista e individualista, reafirmado el liberalismo conservador."

En ese contexto, siguiendo a Gentili (2008, p. 64), “[...] América Latina es la región más injusta del planeta. En ella, la diferencia entre ricos y pobres se multiplica y amplía creando un abismo que parece insuperable para la mayor parte del pueblo." Todo se globalizó o se globaliza en la sociedad pasando a exigir un elevado porcentaje de conocimiento, pues, el fenómeno de la globalización produjo y produce cambios radicales en el mundo del trabajo.

En el contexto del mundo del trabajo podemos afirmar que la principal característica capitalista es que la fuerza de producción ha asumido la forma de mercado, donde los trabajadores producen para el capital y no para sí mismo, convirtiéndose así en un simple objeto de producción. Siendo así, el conocimiento en la contemporaneidad es también un valor mercantil del cual el "capital” necesita para su continuidad. 
En el contexto del mundo del trabajo, podemos decir que la característica principal es la producción de fuerza capitalista que ha tomado la forma de mercancía, por lo que el trabajador es un simple objeto de la producción. La escuela juega un rol de gestión en condiciones de producción. Este artículo tiene la intención de pensar la escuela como un lugar de tolerancia y de respeto que propicie el desarrollo de una cultura democrática, por lo que su funcionamiento alienta la participación de todos en la toma de decisiones. El trabajo de la escuela en la gestión, la mayor parte del tiempo, pierde el sentido de espacio de intercambio, construcción y relación social y se asume en las condiciones del mercado y de la producción.

Si bien, hasta hace poco tiempo la mano de obra era importante para el mercado, en el mundo globalizado la fuerza pierde valor y se abre una nueva categoría llamada: sociedad del conocimiento que no es otra cosa que una nueva forma del mercado capitalista. En esa perspectiva los modelos y métodos de producción como el taylorismo, el fordismo y ahora en este tercer milenio la asunción del toyotismo, fueron implantados con la idea de concentrar la mano de obra con vista a la dominación y alienación, a través de los procesos fragmentados, intensificando el papel del trabajador como mero ejecutor, investido por los avances tecnológicos para el control y acumulación de riquezas por parte del capital.

En ese contexto, la cuestión es cómo la educación podrá tener un papel decisivo en cuanto a política pública para los nuevos procesos de gestión escolar que estén orgánicamente articuladas con la construcción de nuevos procesos sociales orientados para la humanización, la ética y los nuevos paradigmas en cuanto a la convivencia humana.

La ofensiva neoliberal o de los gobiernos liberales impone a partir del Consenso de Washington, en 1989, políticas de acción de dominación de la elite financiera internacional a los países más pobres.

Esa realidad, por tanto, fragiliza, desestabiliza y cambia radicalmente el contexto de la política económica contemporánea, cuyos mayores efectos son sobre las políticas educacionales en el escenario del siglo XXI.

En ese sentido, las palabras de Sader (apud MÉSZÁROS, 2005, p. 16):

No reino do capital, a educação é, ela mesma, uma mercadoria. Daí a crise do sistema público de ensino, pressionado pelas demandas do capital e pelo esmagamento dos cortes de recursos dos orçamentos públicos. Talvez nada exemplifique melhor o universo instaurado pelo neoliberalismo, em que "tudo se vende, tudo se compra, tudo tem preço", do que mercantilização da educação. Uma sociedade que impede a emancipação só pode 
transformar os espaços educacionais em shopping centers, funcionais à lógica do consumo e do lucro.

Ahora bien, debemos considerar en esta presentación que, como plantea Casassus (2000), la gestión educativa no es solamente pragmática como podría pensarse, sino que la dimensión política está inscrita en su práctica, la gestión de la escuela está imbricada dentro las políticas educativas que se despliegan desde el Estado como políticas públicas.

\section{POLÍTICA, ESCUELA Y GESTIÓN}

En el interior de nuestras escuelas hay mucha desesperanza y una profunda sensación de impotencia. En ese contexto, las indagaciones son innumerables y constantes a profesores, gestores, en fin a la sociedad en su totalidad. Entender la crisis que sacude a la escuela en este inicio del siglo XXI nos remite a entender sus fuentes históricas, como los caminos o las tendencias para el escenario educacional que nos impulse a actuar de un modo consiente y colectivo y a salirnos del inmovilismo nebuloso que nos arrastra hacia la desesperanza, el individualismo y lamentablemente a la falta de compromiso ético para con la educación.

Las contradicciones vivenciadas en el contexto educativo latinoamericano son el telón de fondo que determina los avances y retrocesos del quehacer cotidiano educativo. La escuela acabó perdiendo su base de conocimiento, de solidez fundamentada teóricamente y perdió la capacidad de emancipar sujetos como interlocutores de un proceso social efectivo para los necesarios y urgentes cambios sociales. Entendemos que la escuela en ese contexto, no consigue romper con esa lógica de salir adelante, y así como afirma Canário (2006, p. 12) “[...] pasamos de la euforia al desencanto.”

Se decidió que la liberalización de los intercambios internacionales, que hasta esa fecha sólo afectaba a las mercancías, se aplicaría también a los servicios. El Acuerdo General sobre el Comercio de Servicios incluía ya a la enseñanza entre los sectores a liberalizar. Para quedar al margen de la aplicación de este acuerdo, el sistema de educación de un país debía ser totalmente financiado y administrado por el Estado.

Dos años antes que la OMC realizara y diera a conocer El Acuerdo General sobre el Comercio de Servicios (1994), la CEPAL (Comisión Económica para América Latina y el Caribe de la UNESCO) plantea que se requiere incorporar progreso técnico al proceso de desarrollo con miras a elevar la productividad "[...] Ello exige una fuerza laboral educada y flexible, que seguramente se verá obligada a cambiar de 
trabajo varias veces a lo largo de su vida." (COMISIÓN ECONÓMICA PARA AMÉRICA LATINA Y EL CARIBE, 1992, p. 19).

Las demandas del mercado comienzan a regular de modo intrínseco las políticas educativas "en pos del beneficio" de los trabajadores y, como resultado de esto, los nuevos diseños curriculares proyectan nuevos perfiles profesionales para el mundo de alta competitividad, capacidad para la resolución de problemas y adaptación a las nuevas realidades socio-laborales. En el mismo año (1994) del Acuerdo General sobre el Comercio de Servicios se produce el Informe sobre Competitividad del World Economic Forum en el cual se afirma que: "Los aspectos relativamente más débiles de los países de América Latina y el Caribe son sus recursos humanos." (ACUERDO GENERAL SOBRE EL COMERCIO DE SERVICIOS, 1994, p. 34).

Este resurgimiento de la Teoría del Capital Humano, tiene un costo muy alto para los sectores menos favorecidos: la política de desregulación estatal sigue generando un ensanchamiento más profundo entre quienes quedarían dentro y fuera de este nuevo escenario social.

Desde esta perspectiva se comienza a poner el énfasis de las políticas educativas en la modernización de la educación, identificada con la privatización y la disminución del rol del Estado (MIÑANA BLASCO; RODRÍGUEZ, 2003). La modernización educativa se convirtió en bien deseable a través de la reformas y estas estuvieron vinculadas a la crisis económica nacional y global, la crisis de legitimación del estado (GINSBURG, 1991; GINSBURG et al., 1990).

Debemos recuperar la esencia de la educación pública como espacio de inclusión social para la mayoría, siguiendo a Paulo Freire, para los "harapientos del mundo", esto nos exige la consciencia de pensar los modelos de la lógica de capital hacia la lógica dialéctica, esto es, un continuo proceso histórico de construcción y de-construcción constante para aprender a hablar con el otro, no solamente para el otro. Creer en la historia como posibilidad y no como determinismo. El empobrecimiento de la gran mayoría de la población es una construcción humana e histórica y no una determinación divina.

En la actualidad, el modelo neoliberal exhibe una nueva humanidad des-humanizada (GARRETÓN, 1999; SVAMPA, 2005) e injusta, que requiere una mirada, que creemos, asume características particulares en el contexto latinoamericano, realidad tan particular como la de otras regiones, pero identificable por factores y condicionamientos propios. Esto nos compromete no sólo a pensar y a hacer una lista de los problemas que los países centrales no tienen, sino a asumir la responsabilidad sobre los problemas latinoamericanos que exigen un abordaje singular. Es aquí donde 
la sensibilidad intelectual y la capacidad de estar atento a los problemas emergentes juegan un papel determinante al momento de pensar, cuestionar e intervenir sobre las experiencias educativas.

Existe la necesidad de establecer modos de intervención en tanto realidad educativa propia, es decir no copiadas, y en algunos casos reactivas y contestatarias, con estrategias profundamente arraigadas en nuestra manera de ver nuestros problemas y necesidades, desde el sentir de nuestra propia tierra: la riqueza de culturas y tradiciones; las situaciones de inequidad social signada por la explotación por sectores neocolonialistas; la profunda asimetría en la distribución de sus recursos; la precarización laboral y la restricción a los beneficios tecnológicos, entre los principales.

El carácter hegemónico del modelo neoliberal exige una mirada crítica desde el contexto latinoamericano, centralmente en relación con la fuerte incidencia de perspectivas teóricas acuñadas en los países centrales y su efecto legitimador de ciertas ideologías y perspectivas epistemológicas. Por tanto, la gestión educativa debe ser pensada desde la propia realidad.

Es necesario destacar en ese escenario, la actuación e intervención del Banco Mundial en la elaboración e implementación de las políticas públicas educacionales en América Latina para atender los intereses del "capital internacional". Por lo tanto, no nos engañemos, las políticas públicas están para atender los intereses de ajustes que el mundo globalizado impone a los más pobres y la escuela es tributaria de ese proyecto.

En tanto, este escenario es complejo y marcado por las profundas incertidumbres en cuanto a las condiciones de vida digna en busca de la realización humana en su trayectoria. Tales complejidades desencadenan una profunda crisis de razón predominante en las sociedades occidentales, pues siguiendo a Ferreira (2003, p. 29), "[...] hoje o ser humano está perdido à deriva do que fazer e como se realizar." Los efectos catastróficos de ese proceso evidencian principalmente el vaciamiento del Estado como garante para atender los derechos básicos del ser humano. Particularmente en la educación pública.

Para Gramsci (1987, p. 37), “[ ...] o elemento popular sente, mas nem sempre compreende ou sabe: o elemento intelectual sabe, mas nem sempre compreende e especialmente sente."

Los enfoques y las discusiones sobre gestión en educación son recientes y aparecen como innovaciones o superación de conceptos limitadores como el de administración trayendo para la gestión la importancia del elemento humano como articulador, posibilitando así las condiciones para mejora de la calidad de enseñanza 
y transformación de la propia identidad de la educación en América Latina y de sus escuelas que siguen presentando problemas en cuando a líderes competentes. Hasta hace poco tiempo, el análisis e investigación sobre la dirección escolar era, casi, una tarea rutinaria. Cabía indagar al director, si velaba por el buen funcionamiento de la escuela, si tomaba de un modo apropiado las decisiones, y administraba con competencia los eventuales imprevistos.

Al final de la década del 90' del siglo XX y en este inicio del siglo XXI esa situación cambio. Las grandes y continuas transformaciones sociales, científicas y tecnológicas pasaron a exigir un nuevo perfil de director, y por tanto de indagación e investigación, con formación y conocimientos específicos para el cargo y la función de director-gestor para la superación de las dificultades cotidianas. Según Ferreira (2003, p. 19), “A questão real que se coloca é sobre o papel da gestão democrática da educação como prática política responsável e coerente."

Claramente en este inicio del siglo XXI en los procesos escolares se debe comprender la importancia de la gestión como articulación de procesos, con capacidad para el diálogo. No caben más en la educación contemporánea "discusiones atrincheradas" o "reflexiones solitarias", que se pierden en sí mismas o como máximo alcanzan pequeñas reformas o "acomodamientos", es necesario provocar cambios urgentes para una sociedad más humana. Si esto no ocurre, se produce desesperanza e inmovilismo, o peor aún, comienzan a surgir las "verdades absolutas" que no posibilitan avanzar más allá de constataciones y modernismos. Como afirma Gramsci (1987, p. 22):

Como é possível pensar o presente, e um presente bem determinado, com um pensamento elaborado por problemas do passado, muitas vezes bem remoto e ultrapassado? Se tal acontece significa que somos anacronistas em nosso próprio tempo.

Comprender el contexto de las prácticas de gestión en nuestras escuelas es entender que, como afirmaba Gramsci "o velho não morreu e o novo não nasceu”, o sea lo cotidiano de la gestión escolar está permeado por esa contradicción.

Entonces, y tal como sugerimos en el párrafo anterior, no se trataría de gestión educativa, sin más. Sino de gestionar para fundar. Esto es, poner a trabajar condiciones que produzcan, al menos, ráfagas de sentido: un devenir. Desde esta perspectiva estamos planteando una contra hegemonía de lo que surgiera en su momento como gestión educativa, dado que en América Latina, como hicimos referencia al principio del artículo, su aparición data de 1980 y está cargada de un fuerte talante político que se manifiesta con el quiebre del Estado garante de los servicios públicos, 
que dio paso a otro sistema en el que el Estado tiende a reducir su función a la fijación de objetivos, valores y aspiraciones. Evidentemente, la retórica que acompaña a estos cambios, por parte de quien los patrocina, es que suponen una ganancia en la libertad social y personal, una recuperación en la capacidad de iniciativa y de actuación libre (CONTRERAS, 1999, p. 4).

En este sentido, debemos considerar que la autonomía puede estar muy cerca del aislamiento. Si se confunde descentralización y autonomía institucional, con dejar las escuelas libradas a su suerte, el efecto está garantizado: será la legitimación de la inequidad.

Por las razones esgrimidas se manifiesta claramente que la categoría de gestión educativa está cargada de sentido e ideologías, desde allí proyectaremos la gestión institucional: como realidad extraña y, desde la perspectiva crítica, como parte de nuestra propia realidad.

De esa forma, la escuela pasa a cumplir el papel de educar a los "pobres" para servir mejor a los que históricamente pensaban y piensan la sociedad.

En ese sentido, pensar la educación en el contexto de globalización es pensar en gestión de procesos, en la educación, en el papel de gestión educacional. Le corresponde a la gestión de la educación no solamente tomar consciencia y hacer críticas individuales, sino más bien buscar una responsabilidad conjunta más allá de las conciencias individuales donde en realidad todos sean sujetos de proceso, esto es, praxis coherente. Eso implica profundos cambios y de superación en las relaciones entre los sujetos que todavía son marcados por el autoritarismo y por una fachada de diálogo que no pasa muchas veces de falsa generosidad.

Ese es un camino arduo, pues el contexto de la globalización individualiza cada vez más el ser humano en nuestro siglo y es marcado por muchas dudas y pocas certezas.

Retomando el foco de nuestra discusión en cuanto al perfil de gestión en una cultura globalizada, nos cabe situar a los contextos educacionales construidos en modelos extremamente autoritarios, tecnicistas y fragmentados, que provocan prácticas esponatenístas de gestión.

En este inicio del tercer milenio, en la contemporaneidad, quien manda en la escuela? Los profesores, los alumnos, los funcionarios, la directora o el director, la secretaría de educación, o los gobernantes. Quién manda de hecho en educación en el contexto de globalización?

Por las nuevas leyes de educación en Latinoamérica en la década de $1990^{2}$ y que luego obtuvo cambios en la década de $2000^{3}$ pero sin llegar a transformar la 
realidad del continente latinoamericano, en tanto la comunidad educacional trabaja genéricamente esos desafíos.

Nuestra actuación en mundo y con el mundo debe constituirse en una actividad transformadora de la realidad social.

La sociedad del conocimiento nos exige otra escuela para un mundo de constantes cambios. Hay necesidad de repensar los "modelos" que no responde más al contexto de la sociedad contemporánea.

De acuerdo con Lück (2006, p. 29-30):

As deficiências em gestão ocorrem por falta de referencial, organização e orientações adequadas para nortear a atuação educacional com a devida competência. Desperdiçam-se recursos, tempo e, o que é mais grave, talento humano, com sérias repercussões sociais, quando se entende que os problemas de ensino são apenas de natureza didática, e não de gestão pedagógica, a serem resolvidos envolvendo, de forma dissociada, novas técnicas e exercícios de ensino, mais materiais escolares, capacitação de professores, sem esforço em articular e coordenar a proposta pedagógica e processos correspondentes, dinamizando-os de forma criativa, sistemática e contínua.

Constatamos que modelos de gestión cerrados en sí mismos solamente refuerzan las injusticias sociales de todo orden. Entretanto, las instituciones educacionales, de un modo general, todavía no tomaron consciencia de crear una gestión ágil, dinámica y comunicativa para el emprendimiento de su plano de acción. El principal desafío que se impone hoy a la gestión de la escuela es redefinir la cultura organizacional instaurada. Sin ese cambio, otras innovaciones corren el riesgo de tornarse ineficaces.

Que podamos delante de la complejidades, ser sensibles, solidarios y comprometidos políticamente con la construcción de un mejor, en que la vida de nuestros niños, adolescentes, jóvenes y adultos de las escuelas públicas no nos sean indiferentes.

Reflexionar sobre el papel de la gestión para el siglo XXI, es crear condiciones para la autoconsciencia que solo se dará por el conocimiento que nos exige otra calidad y cantidad para un nuevo perfil de gestión. La educación continua de la gestión no puede quedar a merced de los discursos en el contexto de la sociedad del conocimiento.

El desarrollo de la investigación apunta aspectos importantes relativos a la forma en que los gestores ven, entiende y evalúan la actual situación de su práctica en el cotidiano escolar, revisando su actuación en un período histórico caracterizado por profundos cambios. 
El hecho que las situaciones en el mundo del trabajo, en el mundo social, cultural y educacional ha demandado nuevas posturas por parte de los gestores y de su cuerpo docente.

En tanto sabemos que, tanto las estructuras burocráticas, como las humanas, rigen de forma lenta las implicaciones sobre los cambios. Conocer el pensamiento sobre la formación de la gestión puede pronosticar efectivos cambios en la estructuración de la educación permanente, tanto como las posibilidades de cambios en la formación de los futuros gestores.

Podemos afirmar que la cuestión de la gestión podrá tener modificaciones cuantitativas y cualitativas y que la implementación de estas modificaciones depende, en gran parte, de la comprensión que los gestores tienen de su papel. Sabemos que las acciones que pueden y deben ocurrir dentro de las instituciones solo tendrán efectos si la escuela, y sus agentes, modifican la visión de su papel en cuanto a la formación del alumno y, por consiguiente, modifican la organización y estructuración de las actividades curriculares en su Proyecto Pedagógico.

Podemos decir que el debate sobre la gestión, procura buscar superar, a través de una nueva cultura de formación del gestor, la falta de referencia teórico en aspectos fundamentales de la sociedad, la civilización y de la cultura. Podemos decir, que las perspectivas actuales están más abarcadoras y engloban aspectos de totalidad en la formación de los gestores.

Estos elementos claves y extremadamente necesarios para tener en cuenta: integración de los conocimientos; compromiso ético; actualización continua del conocimiento; consideraciones de los aspectos sociales en el desarrollo de las investigaciones y de las actividades profesionales; comportamiento investigativo.

La escuela como institución en su larga existencia, ha sido marcada por discusiones que reflejan, fundamentalmente, posiciones divergentes en cuando a su finalidad y función, lo que lleva necesariamente, a diferentes posicionamientos en relación a su organización. Esos posicionamiento, que marcan diferenciaciones en la forma de planearla, explicitan funciones de las más dispares que van desde entenderla como una institución esencialmente burocrática o como un espacios de expresión de construcción de otras posibilidades.

Todas esas tensiones y contradicciones muestran la importancia de la discusión de las cuestiones relativas a la gestión y revelan que esa ha sido una tarea de grandes proporciones, una vez que la educación es permeada por la complejidad de la sociedad moderna. 
Por ser los gestores los agentes e acción escolar, el conocimiento sobre las concepciones que tienen respecto de la finalidad de su formación, del papel de la institución escolar, se torna de gran importancia.

Viviendo en un tiempo de grandes cambios sociales y culturales, los gestores demuestran su preocupación por la necesidad de cambios en su formación; en tanto, se encuentran confundidos sobre la dirección que estos deben tomar. Conocer y explicitar esos cambios es contribuir de forma significativa a una mejor y coherente acción pedagógica.

La cuestión de una formación más amplia y cultural siempre estuvo en las discusiones. Es importante considerar que los gestores reconocen la importancia de esa formación general para entender el mundo actual.

Es un hecho que las situaciones actuales, han demando nuevas posturas de las instituciones educacionales y de su cuerpo docente. En tanto, sabemos que la estructuras tanto burocráticas como las humanas, reaccionan de forma lenta a los cambios. Así, que el cuerpo de gestores de las instituciones escolares se presenta en diferentes fases de percepción y actuación. Queremos, como resultado de investigación, auxiliar a los gestores y administradores públicos a tener mejores parámetro para actuaciones integradas y coherentes.

La conceptualización de la gestión educativa que deviene del pensamiento neoliberal, de la realidad extraña, posee dos pilares centrales: la racionalidad económica y la moral del hágalo usted mismo. La racionalidad económica refiere a un tipo de inteligibilidad del mundo que nos dice que la economía es el principio estructurador de la vida. El sujeto - en esta racionalidad - es el sujeto de interés, que desplazó al viejo sujeto de la razón. Se trata de un sujeto irreductible a la ley y sometido al cálculo costo-beneficio. De esta forma se constituye el sujeto de cálculo: impacto y beneficio serían los términos centrales de la gestión educativa. Porque ese sujeto de interés traslada su modo de operar a la modalidad de gestionar. Es aquí donde los mecanismos económicos invaden la realidad de la escuela, reconociendo que existe un "usuario" que no necesita del Estado.

Desde aquí podríamos decir que no es inexplicable que determinados términos circulen actual-mente alrededor de los discursos educativos: management, calidad total, escuela inteligente, impacto, beneficio, reingeniería, normas ISO. Una gran dificultad que se planteó desde este discurso estuvo inherentemente vinculada a la cuestión disciplinar, un enfoque disciplinar neoliberal, una epistemología neoliberal. A decir de Casassus (2000) un problema que se dio en Latinoamérica tiene que ver con la ausencia de la dimensión educación en la gestión educativa. 
Así, la gestión educativa se convirtió en el espacio de la aplicación de los principios generales de la gestión, sin más. Cuando en realidad se suponía que disciplinarmente ambos campos debían converger para abordar la problemática, pero esto no es casual o no es parte de una incapacidad epistemológica, sino que ingresa claramente en la lógica neoliberal de la conducción educativa. Estas funciones han sido aplicadas a la gestión educativa y de allí los términos/criterios que mencionábamos en líneas anteriores como extrapolados, pero tan necesarios al momento de pensar una economía de producción: ¿la escuela?. En una economía de producción los criterios son claves al momento de pensar en procesos de (re) asignación de recursos, determinar con precisión el producto, medir el rendimiento del sistema, determinar el ámbito y niveles de calidad, referirlo a estándares y a partir de ello, alinear procesos para mejorar la productividad (eficiencia) y el producto (eficacia). ¿Hacemos referencia a la escuela?

Un nuevo término hizo su aparición en la escena educativa: management. Palabra de origen anglosajón que significa dirección, gerencia, organización, que es adoptada por el discurso educativo en aras de repensar las estrategias de optimización del servicio. Al igual que cualquier otra agencia del mercado, la escuela es ahora un servicio y - en tanto servicio - más que institución se convierte en mera organización.

Como se puede observar, la lente con que se observa la realidad, en tanto gestión educativa, en muchas ocasiones es la demanda del neoliberalismo pedagógico. Si lo que cuenta son las nuevas demandas del mercado, sólo se tratará de amoldar la escuela para que se corresponda con el imperativo emergente.

Ahora bien, si decidimos tomar otro camino, en la división de las aguas, optaremos por analizar los efectos que produjo el neoliberalismo en la sociedad, la subjetividad y por ende la gestión educativa, intentando desanudar los problemas producidos y potenciar las posibilidades subjetivas.

Es aquí donde queremos presentar algunos de los postulados propios de la gestión educativa en la realidad latinoamericana, pero antes debemos considerar, como hicimos mención en líneas anteriores, el quiebre de la institución escolar. Esto es, asumir que el sentido de la misma está deteriorado. En otro trabajo afirmamos que habitamos el sin-sentido de la escuela en esto que ya no es la modernidad.

Sin duda que debemos posicionarnos en el contexto actual, como contexto transicional: modernidad y esto que ya no es, esta es la cuestión que debemos asumir como educadores: es otro el tiempo que habitamos.

Porque no sólo se trata de una época de grandes cambios, sino de un cambio de época, donde lo viejo se derrumba y lo nuevo no alcanza a aparecer, lo cual tiñe la existencia por el malestar y la incertidumbre. Las certezas conquistadas por la 
Modernidad son socavadas por las turbulencias de los cambios que desnudan las limitaciones de la comprensión humana para entender lo que está sucediendo así como avizorar las tendencias a futuro. En eso consiste... en que los que actualmente habitamos la sociedad, la escuela y las instituciones, somos partícipes o espectadores de este tiempo de cambio social, político y económico. Por esta razón es muy difícil responder al sentido actual de la escuela, porque el sentido se desconfiguró.

La transmisión de la cultura, como decisión política, comienza a fraguar cuando se percibe que el formato escolar moderno se ha consumido. A tal punto que Guillermina Tiramonti (2004) pregunta ¿se puede hablar de sistema educativo en la actualidad? El mismo requiere de ciertas características: significación social de los procesos de transmisión cultural y cierta correlación entre la cultura escolar y la cultura social.

El diccionario ofrece entre varias acepciones, la siguiente, que es la que consideramos pertinente a los efectos de la propuesta: Sentido, Finalidad o razón de ser: este texto absurdo carece de sentido (LARROUSE, 2005).

De este modo, tenemos como desafío analizar la escuela como texto cuya finalidad o razón de ser, en la actualidad, está muy cerca de ser un texto absurdo. Si la escuela está en estas condiciones, nos permitimos la pregunta ¿cuál es su finalidad?

Tiramonti (2004, p. 11) advierte: "[...] es claro que habitamos un espacio de derrumbe de las certezas conceptuales, de los mitos identitarios de la nación y de las instituciones con las que se tejió el entramado de la sociedad moderna."

En este trabajo proponemos una mirada, una perspectiva; consiste en encontrar, buscar, sentir las ráfagas de sentido, que en principio no nos conducirá a la razón de ser - como planteaba nuestra definición del diccionario- pero en la simultaneidad de ráfagas de sentido, en la conjunción y en el debate como camino, y con la paciencia que no es propia de la cultura de lo instantáneo del tiempo actual, los educadores podremos buscar y nombrar estas ráfagas que seguramente se posicionaran ante nosotros como aires novedosos.

Y es aquí donde la gestión educativa debería ocupar un rol central en nuestra Latinoamérica. Los educadores como intelectuales ¿qué papel ocupamos en esa reconstrucción del quiebre de las instituciones educativas? ¿Qué aporte podemos tomar de la gestión cuando nos damos cuenta de que las instituciones así, no van más? ¿O el neoliberalismo será el agente encargado de dar nuevos sentidos a la escuela, convirtiéndola en dispositivo reproductor de su hegemonía?

Aquí hacemos referencia a los fenómenos educativos y particularmente, al modo en que se habita; habitar hoy la institución escolar es afrontar la responsabili- 
dad de la transmisión cultural, de la transmisión del conocimiento. Llevar a cabo un proyecto de gestión educativa que re-piense y fundamente los sentidos de la escuela.

Para esto es necesario comenzar a restituir desde la propia gestión educativa, como plantea Duschtatzky e Birgin (2001), pensar la gestión educativa como capaz de generar ráfagas de sentido, dado que en medio de la confusión que vive la escuela la gestión educativa neoliberal se muestra muchas veces como la panacea a las dificultades. Esta restitución trae, inherente a sí, la de idea de invención.

\section{CONSIDERACIONES FINALES}

La restitución tiene que dar espacio a las ráfagas de sentido, de las cuales devienen la capacidad de generar. Generar una nueva escuela. Existe pues una gran diferencia entre reinvención desde el management y la apuesta por la invención de un pensamiento de la gestión educativa en Latinoamérica.

Latinoamérica es contagiada por las influencias e interferencias externas, donde las marcas de los antiguos colonizadores aparecen fuertes, en un proceso alternado de dominio, resistencia y sumisión. Cada país ha sido de algún modo expropiado y ha sufrido así el continente latinoamericano que viene intentando a su modo, con sus tiempos y en las condiciones posibles implementar cambios sociales y buscando procesos democráticos. Por lo tanto, las ideas y la fuerza de la dominación impuesta por los invasores persisten, de manera confusa, en los diversos segmentos de la sociedad. Entre tantos otros, el tema de la educación es permeado en nuestros países.

La potencia de la gestión está vinculada al conocimiento sensible, señala Blejmar (2001) gestionar supone un saber, pero no un mero saber técnico, sino un saber sobre la situación en la que se interviene: la escucha atenta, la propuesta, crear condiciones para pensar, rediseñando sobre la marcha, buscando. Aquí nos hemos aproximado nuevamente a una definición que, creemos puede ser interesante en nuestras latitudes, que no pertenece a los países centrales.

La gestión se da en la situación concreta de la escuela, por tanto no se libera de los obstáculos y la realidad, gestionar es hacer que se produzca el movimiento de comenzar a habilitar la posibilidad de ráfagas, en oposición a la completud, a la armonía del "todo está bien". Probablemente esto duela un poco, carcoma, pero debemos afrontarlo como momento de transición. En la búsqueda de un norte asumimos las palabras de Nietzsche (2003, p. 189) para comenzar a gestionar la escuela en Latinoamérica.

Gestionar implica crear condiciones. El trabajo de gestión irá más allá de listar debilidades y fortalezas, consiste en un insistente esfuerzo por leer críticamente 
el mundo, para cambiar lo que hoy pasa de una manera injusta (FREIRE, 1997); en la esperanza radical sustentada en la siempre posibilidad de transformar el mundo porque en cuanto existente, el sujeto se volvió capaz de participar en la lucha por la defensa de la igualdad de posibilidades. Por tanto, y considerando la realidad extraña, la gestión institucional es posibilidad de democratización y análisis crítico de la realidad social.

La gestión encuentra muchos límites en su acción. Así, límite no es aceptar la condición de inmovilización, sino una invitación a la creatividad, a la superación, ir por más de lo que se espera y quieren de la propia gestión. El límite debe significar el ansia, la búsqueda de una educación ética, integral y ciudadana. Los desafíos de la gestión en la era de la velocidad, de la información, del capitalismo salvaje, de la globalización masificante son muchos! Cuáles son los relevantes? Cómo buscar en la desigualdad la unidad? Cómo buscar la igualdad en las diferencias?

En cuanto al Estado desempeñar apenas la función de regulador y evaluador, estará cumpliendo plenamente los objetivos propuestos por los organismos internacionales y la educación ocupará el dentro de las atenciones de esas entidades, las cuáles, en colaboración con facciones nacionales, continuaron definiendo el orden educación mundial. Será siempre una educación utilitarista visualizada como instrumento de promoción del crecimiento económico, formando y formateando "capital humano" adecuado a los intereses del mercado.

La reformas educativas van hacia esta perspectiva transfiriendo a los docentes grandes responsabilidades y hasta enfatizando su formación, a fin de operacionalizar los objetivos pretendidos con el nuevo papel de la escuela siguiendo las regulaciones establecidas en el proceso de mundialización.

Así, buscamos hacer un abordaje articulad con conceptos de administración y gestión y los desdoblamiento de ese proceso. Destacamos algunos de los nuevos paradigmas gestores - sin que estos signifiquen la simple adopción de nuevos padrones gerenciales, identificando los eventuales avances en los procesos de gestión de las políticas públicas. Así como hemos señalado aspectos considerados carentes, identificados como límites y obstáculos de gestión.

En el campo educativo, prácticamente en la mayoría de Latinoamérica ocurre una cambio en el papel social de la educación y de la escuela que altera el panorama de la educación básica. Por lo tanto, es en esa contradicción que la política educativa acontece. Así, al mismo tiempo, cumple un papel para el mercado en tanto políticas públicas y se sitúan en el ámbito de las políticas sociales. Fue en esa vivencia contradictoria que acontecieron avance y retrocesos y en ese contexto la educación comenzó a ser comprehendida como práctica social. 
Se trata, entonces de ampliar los horizontes de escuela en cuanto institución social, pus la gestión es participativa, en el ámbito específico del proceso de trabajo, se define, también en oposición al taylorismo y el "compromiso fordista", especialmente en lo que se refiere a los principio de separación radical de tareas de concepción y de ejecución, de la fragmentación y de la especialización de las tareas.

La definición del término gestión escolar de carácter participativo, posibilitaría mayor participación de los trabajadores y mayor capacidad de intervención en los procedimientos administrativos. Representa una conquista en tanto amplía la intervención de los trabajadores en la cuestión del poder, de la autoridad que representa una brecha en el sistema de poder ya que amplía el espacio de participación.

Gestión y administración, es toma de decisión y organización, y dirección. Se relación a la actividad de impulsar una organización y sus objetivos, cumplir su función de desempeñar su papel. Se constituye de principios y prácticas que afirmar o des-afirman los principios que la generan. Estos principios, en tanto no son intrínsecos se concibe a la gestión como administración clásica, pero son principios sociales, visto que la gestión de la educación se destina a la promoción humana es un término que, históricamente se viene afirmando en el ámbito de la administración de la educación y en el estudio de instituciones y organizaciones, incluyendo las educacionales, como sinónimo de la administración que se instala en el mundo pensante con un sentido más dinámico, traducido en movimiento, acción, movilización, articulación.

La libertad y la gestión democrática pasan a ser fundamentales para consolidar la educación para el pleno desarrollo del ser humano y para el ejercicio de la ciudadanía. Contradictoriamente a ese discursos oficial, las políticas de gestión para la educación se efectivizan a partir de las acciones de cuño gerencial para garantizar optimización de los recursos y racionalización administrativa. De ese modo, para los gobiernos, los problemas educacionales no provienen de la escasez de recursos y si de la mala administración, del corporativismo de profesores, de la baja cualificación y de la ineficiencia del aparato administrativo y burocrático de las escuelas.

Hablar de calidad de la educación a partir de la lógica de mercado es limitar y medir un campo fértil de aprendizajes diversificados, de diferencias, de experiencias únicas, de relaciones diversas... E invertir valores, y cambiar lo que debería ser el fin por el medio, pues la calidad no está solo en los resultados, sino en el propio proceso, en la transformación, en la relación entre personas que ocupan posiciones diferenciadas del profesor y alumnos, esto es: no abandonar el pensamiento crítico que permita responder por sus deberes y sepa reclamar sus derechos. 
Cuando vinculamos calidad educativa con evaluación tenemos como presupuesto la idea de concebir esta calidad a parir de indicadores que en general están anclados en el poder. En Latinoamérica los indicadores fueron establecido a partir de la óptica de la Organización para la Cooperación y Desarrollo Económico (OCDE), proveniente de los países "desarrollados", con alto poder económico y de decisión, por lo tanto, de contextos opuestos a los nuestro, los cuales impusieron las metas que debemos alcanzar en la próxima década (2022), superadas por ellos en la década anterior. Desconsiderando establecer esas metas desde el paradigma de Latinoamérica. Queremos y precisamos una educación de calidad ahora, en el presente y no en el futuro. Educación de calidad ciudadana y derecho de todos y no caridad de algunos.

Notas explicativas

\begin{abstract}
${ }^{1}$ El Acuerdo General sobre el Comercio de Servicios (AGCS, GATS por sus siglas en inglés) es uno de los acuerdos de mayor alcance de la Organización Mundial del Comercio (OMC). Su propósito es liberalizar progresivamente el "comercio de servicios" entre los miembros de la OMC.

${ }^{2}$ Brasil, Lei de diretrizes (1996); Argentina, Ley Federal de Educación (1993); Uruguay, Reforma Rama (1995); Chile, Ley Orgánica Constitucional de Enseñanza (1990); México, Ley General de Educación (1993), Bolivia, Ley de Reforma Educativa (1994).

${ }^{3}$ Chile la Ley n. 19.876 de 2003; Argentina (2006) Ley de Educación Nacional; Bolivia (2010) Ley de Educación "Avelino Siñani y Elizardo Pérez"; Brasil (2009) enmienda a la Lei de Diretrizes y Bases de 1996; Ecuador (2011) Ley Orgánica de Educación Intercultural México (2004) Reforma de la Ley General de Educación; Perú (2003) Ley General de Educación; Uruguay (2008) Ley general de Educación.
\end{abstract}

\title{
REFERENCIAS
}

BALL, S. J. Grandes políticas, un mundo pequeño. Introducción a una perspectiva internacional en las políticas educativas. En: NARODOWSKI, M. (Org.). Nuevas tendencias en políticas educativas: Estado, mercado y escuela. Buenos Aires: Granica, 2002.

BLEJMAR, B. De la gestión de resistencia a la gestión requerida. En: DUSCHATZKY, S.; BIRGIN, A. Dónde está la escuela? Ensayos sobre la gestión institucional en tiempos de turbulencia. Buenos Aires: Manantial, 2001.

CARNOY, M. Están Funcionando Las Reformas Educativas En Latinoamérica? Nuevas Perspectivas. Documento de Trabajo. Washington, DC: BID, 2002.

CASASSUS. Problemas de la gestión educativa en América Latina. Chile: Unesco, 2003.

CONTRERAS, J. D. Autonomía por decreto? Education Policy Analysis Archives, College of Education Arizona State University Online, v. 7, n. 17, 1999. Disponible en: <http://epaa.asu.edu/ojs/>. Acceso en: 15 marzo 2014. 
CORAGGiO, J. L. Desarrollo Humano y Política Educativa En La Ciudad Latinoamericana. In: SEMINARIO INTERNACIONAL "EDUCACIÓN POPULAR Y UNIVERSIDAD”, 3., 1994, João Pessoa. Anales... João Pessoa, Brasil, 1994.

DUSCHATZKY, S.; BIRGIN, A. Dónde está la escuela? Ensayos sobre la gestión institucional en tiempos de turbulencia. Buenos Aires: Manantial, 2001.

FERREIRA, N. S. C. (Org.). A gestão da educação na sociedade mundializada: por uma nova cidadania. Rio de Janeiro: DP\&A, 2003.

FERREIRA, N. S. C. (Org.). Formação Continuada e Gestão da Educação. São Paulo: Cortez, 2003.

FREIRE, P. Pedagogia da Autonomia: saberes necessários à prática educativa. São Paulo: Paz e Terra, 1996.

FREIRE, P. Pedagogia do Oprimido. Rio de Janeiro: Paz e Terra, 2005.

GARETÓN, M. Latinoamérica un espacio cultural en un mundo globalizado. Bogotá: Convenio Andrés Bello, 1999.

GENTILI, P. Desencanto e utopia: a educação no labirinto dos novos tempos. Petrópolis: Vozes, 2008.

GISBURG, M. B. et al. National and World System Explanations of Educational Reform. Comparative Education Review, v. 34, n. 4, p. 474-499, 1990.

GISBURG, M. B. Understanding Educational Reform in Global Context. Economy, Ideology and the State. Nueva York: Garland, 1991.

GRAMSCI, A. Obras Escolhidas. São Paulo: Martins Fontes, 1987.

KAES, R. Transmisión de la vida psíquica entre generaciones. Buenos Aires: Amorrortu, 1996.

LÜCK, H. Concepções e processos democráticos de gestão educacional. Petrópolis: Vozes, 2006.

LÜCK, H. Perspectiva da Gestão escolar e implicações quanto à formação de gestores. Brasília, DF: Cadernos em Aberto, 2000.

MÈSZÁROS, I. Educação para além do Capital. São Paulo: Boitempo, 2005. 
MIÑANA, B. C.; RORIGUEZ, J. "La educación en el contexto neoliberal" en La falacia neoliberal. Crítica y alternativas. D. I. Restrepo Botero. Bogotá: Universidad Nacional de Colombia, 2003.

NIETZCHE, F. Así Hablo Zaratustra: un libro para todos y para nadie. Madrid: Alianza Editorial, 2003.

SAVIANI, D. Escola e Democracia. 31. ed. São Paulo: Autores Associados, 1997.

SYAMPA, M. La sociedad excluyente. La Argentina bajo el signo del neoliberalismo. Buenos Aires: Taurus, 2005.

TIRAMONTI, G. La trama de la desigualdad educativa. Buenos Aires: Manantial, 2004.

Recebido em: 29 de setembro de 2014

Aceito em: 03 de fevereiro de 2015 
